\title{
LA MELANCOLÍA EN LOS CUENTOS \\ RESTOS DE CARNAVAL Y LA IMITACIÓN DE LA ROSA
}

Graciela Aparicio*

\section{RESUMEN}

En los cuentos "Restos de Carnaval" e "Imitación de la rosa" de Clarice Lispector, la melancolía se presenta como un síntoma contextual de la modernidad. Las protagonistas de estos relatos son absorbidas por la melancolía; viven alienadas y no pueden constituir plenamente su "Yo". Construyen una identificación tan absoluta con el objeto que se lo devoran.

Palabras claves: Modernidad. Melancolía. Identificación. Devorar.

\section{THE MELANCHOLY IN THE TALES "RESTOS DE CARNAVAL" AND "LA IMITACIÓN DE LA ROSA"}

\begin{abstract}
In the tales "Restos de Carnaval" and "Imitación de la rosa" by Clarice Lispector, the melancholy is showed as a contextual symptom of modern life. The main characters of these tales are absorbed by this melancholy; they live alienated without being able to constitute their "Self". They build such an absolute identification with the object that they devour it.
\end{abstract}

Keywords: Modernity. Melancholy. Identification. Devour.

\footnotetext{
* Profesora en letras por el Instituto Nacional del Profesorado "Alicia Moreau de Justo" (ex Normal Nro 1) I.N.E.S. de Ciudad Autónoma de Buenos Aires. Se desempeña como profesora en la Universidad Nacional de Quilmes (UNQUI) de la provincia de Buenos Aires. Actualmente cursa la Maestría en Literaturas española y latinoamericana de la Universidad de Buenos Aires (UBA) Facultad de Filosofía y Letras. E-mail: ge_aparicio yahoo.com.ar
} 


\section{Introducción}

La melancolía resurge con el hombre moderno que mira cómo se agiganta el mundo a su alrededor. Emerge del asfalto una nueva ciudad que lo sorprende y lo aliena convirtiendo la música de la naturaleza en el bullicio de la industrialización.

El progreso se yergue como un monstruo que coloca al hombre en un torbellino y lo deja recogiendo los restos de un universo que sólo es valioso para él, en soledad.

El capitalismo inviste a la historia de una eternidad circular que gira entorno al progreso. La masificación convierte a los hombres en espectros que manipulan las nuevas herramientas del futuro.

El hombre mira el vacío de su entorno e intenta en su desesperación asir el objeto que lo colme y le devuelva su estabilidad.

Como un coleccionista el hombre contempla los objetos despojados de sentido $\mathrm{y}$ en un intento de reconstruir su yo desmembrado quiere tomarlos e incorporarlos vorazmente. Busca un espacio de reconocimiento y un objeto de pertenencia e identificación para colmar su vacío espiritual.

Su libro único y salvador se convierte en valor de mercado. La fugacidad del tiempo deja de ser un temor para ser una realidad palpable que se eterniza y muere en una fotografía instantánea.

El melancólico se evade y se refugia en el recogimiento y la reflexión. La tarea artística aparece, entonces, como un instrumento salvador que permite la trascendencia y la sublimación de los deseos.

La narrativa de Clarice Lispector refleja la angustia de vivir, la necesidad de liberación y la búsqueda de una identidad que se desintegra y se reconstituye ante el peligro de las fauces de Saturno y la modernidad.

Inmersa en el espíritu saturnino, Clarice Lispector diseña las máscaras que le permiten ser "otra" en un universo carente de identidad. Ana Luiza Andrade dice sobre Clarice Lispector:

É a partir de uma consciência descontínua da história moderna entretecida, na multiplicidade transitória de máscaras em que se encarna involuntariamente o escritor, em sua necessidade de ter/ser outros, e ainda como uma filha devotada de Saturno, que Clarice Lispector se apresenta (ANDRADE, 1998, p. 152). 
Probablemente, a través de la literatura, Clarice Lispector pudo enfrentar los fantasmas del Eros y, con la palabra, corporizar sus deseos, mitigar su dolor, desmembrarse y reconstituirse entre la ficción y la realidad.

En los cuentos "Restos de Carnaval"1 y "La imitación de la rosa", 2 la melancolía absorbe a las protagonistas, viven alienadas y no pueden constituir plenamente su "yo". Construyen una identificación tan absoluta con el objeto que se lo devoran.

\section{La Melancolía en los cuentos}

\section{"Restos de carnaval"}

En el cuento "Restos de Carnaval", la melancolía se instala desde el título que nos advierte de una falta, de un dolor que se constituye con el término "restos" y se agudiza al enfrentarse con una antítesis semántica que es la presencia del término "Carnaval". Lo festivo se hace presente y rival de un dolor que amenaza como un fantasma. "Restos" connota un sentido de muerte, lo que queda de un todo, los despojos de una integridad. Son despojos los que el lector va recogiendo durante todo el relato desde la mirada de una niña que intenta rearmar su objeto de amor y de identificación, en una lucha constante contra lo inexorable que le recuerda lo efímero del tiempo de la felicidad.

La narradora, en su recuerdo de la niñez, de cómo eran los días de Carnaval, habla de despojos de serpentinas y confeti. La calle después del Carnaval no está solitaria, sino "tremendamente vacía". Surge la idea de la flor como símbolo frágil, perecedero pero embriagador y como epifanía del mundo. Constituye la esperanza de algo que puede surgir, transformarse en medio del caos aunque su esencia sea inconsistente: "Como si finalmente el mundo se abriera del capullo que era como una gran rosa escarlata" (LISPECTOR, 2008a, p. 62).

El goce por el Carnaval siempre aparece como un goce nostálgico y melancólico, desde la mirada de un espectador, de alguien que nunca puede ser un agente activo al que sólo se le permite contemplar.

\footnotetext{
${ }^{1}$ LISPECTOR, Clarice. Restos de carnaval. In . Revelación de un mundo. Buenos Aires: Adriana Hidalgo editora, 2008a.

2 . La imitación de la rosa. In: Cuentos reunidos. Madrid: Ediciones Siruela, 2008b.
} 
La melancolía no sólo se construye como un sentimiento que enmarca los hechos de la historia sino que forma parte de una confesión desgarradora, de un yo que se desintegra. Y ese dolor la devora destituyéndola del mundo de la niñez: "[...] entraba en contacto indispensable con mi mundo interior, que no estaba hecho de duendes y príncipes encantados, sino de personas con su misterio" (LISPECTOR, 2008a, p. 62).

El festejo del Carnaval se contrapone a la enfermedad de la madre. El fantasma de la muerte se instala y acelera el transcurso del tiempo exigiendo que todo se defina en la inmediatez; en esos tres días la niña debía ser feliz y ser grande, para dejar atrás una infancia llena de dolor y fragilidad, donde nada podía sostenerla.

En un estado de melancolía surge una posibilidad, algo que podría salvar a la manera de un "milagro"; algo diferente puede suceder y cambiar el estado de las cosas, disfrazarse era su sueño. Aunque la posibilidad de tener un disfraz depende de "la sobra", de un "resto" de papel, tiene por sobre todo, la oportunidad de ser "otra": “Aquel Carnaval, pues, por primera vez en la vida tendría lo que siempre había querido: iba a ser otra y no yo misma" (LISPECTOR, 2008a, p. 63).

La niña debe enfrentar una dualidad permanente entre la felicidad y el dolor, entre el deseo de obtener su objeto de amor y la melancolía que le imposibilita desprenderse de ese dolor para poder vivir: "Pero ¿por qué precisamente ese Carnaval, el único con disfraz, tuvo que ser tan melancólico?’(LISPECTOR, 2008a, p. 63).

Es imposible para la niña disfrutar plenamente de esa felicidad ya que ha perdido su objeto de amor. Pero no puede separarse de ese objeto, con el que queda unida y desintegrada como "yo" independiente; sujeto y objeto quedan alienados. En la alienación desaparece el sujeto porque no encuentra un lugar propio. Esto la conduce al deseo y a la necesidad de trascender a través de la otredad, de transformarse a través del disfraz y la máscara.

En el cuadro de la melancolía, al desaparecer el objeto -que si no ha muerto, pudo haberse perdido como objeto de amor- el sujeto no tiene lugar propio, es el objeto el que le otorga existencia. En Duelo y Melancolía, Freud dice al respecto:

Al principio existía una elección de objeto, o sea enlace de la libido a una persona determinada. Por la influencia de una ofensa real o de un desengaño, inferido por la persona amada, surgió una conmoción de esta relación objetal, cuyo resultado no fue el normal, o sea la sustracción, de la libido de este objeto y su desplazamiento hacia uno nuevo, sino otro muy distinto, que parece exigir, para su génesis, varias condiciones. La carga del objeto demostró tener poca energía de resistencia y quedó abandonada; pero la libido libre no fue desplazada sobre otro objeto sino retraída al yo, y encontró 
en este una aplicación determinada, sirviendo para establecer una identificación del yo con el objeto abandonado. La sombra del objeto cayó así sobre el yo; este último, a partir de ese momento, pudo ser juzgado por una instancia especial, como un objeto, y en realidad como el objeto abandonado. De este modo se transformó la pérdida del objeto en una pérdida del yo [...]. (FREUD, 1997, p. 2094-95)

La niña está alienada por su mamá, no tiene energía psíquica para investir otros objetos. El Carnaval podría otorgarle la oportunidad para desprenderse de ese dolor pero el mismo festejo está unido a él, se lo ha devorado la melancolía, sólo son despojos de una felicidad sin consistencia.

El disfraz que logra obtener la niña conlleva la dualidad alienante, por un lado puede tomar la identidad de una flor y por otro, no sólo está construido por restos de papel sino que la misma flor -que en un principio podía simbolizar el nacimiento de algo nuevo y esperanzador- al mismo tiempo tiene una esencia frágil y perecedera.

Todo el escenario que rodea a la niña está conformado por restos, es un espejo de su "yo" desmembrado, no se encuentra la posibilidad de reconstituirlo. Y esta adversidad se vive como una jugada fatal del destino que no permite una explicación racional y que tampoco le otorga respuesta sobre la pérdida de su objeto de amor: "Muchas cosas que me pasaron tan malas las perdoné. Sin embargo, a ésa no puedo ni siquiera entenderla ahora: ¿el juego de dados de un destino es irracional? Es impiadoso" (LISPECTOR, 2008a, p.64).

La melancolía devora el universo de la niña, ha perdido el interés por un deseo propio. Al no poder separarse de su madre, busca ser otra, ser esencialmente una flor.

La niña ha perdido el sentimiento de sí. Acerca de la melancolía, Freud destaca un rasgo particular de dicho proceso:

"El melancólico muestra, además, otro carácter que no hallamos en el duelo: una extraordinaria disminución de su amor propio, o sea un considerable empobrecimiento de su yo" (FREUD, 1997, p. 2093).

El tiempo de la melancolía se construye en un devenir eterno. La continuidad temporal alienante sumerge a la niña en una construcción dialéctica, entre la vida y la muerte, entre el vivir y el contemplar.

Cuando aparece la posibilidad de transformación, su madre empeora. Casi estaba lista con su disfraz, y es ella quien debe ir a comprar un remedio. Este hecho la devuelve al terreno de la melancolía, al deseo inconcluso, a la contemplación de lo que queda por construirse. 
Fui corriendo vestida de rosa - pero el rostro todavía desnudo no tenía la máscara de muchacha que cubriría mi tan expuesta vida infantil-, fui corriendo, corriendo, perpleja atónita, entre serpentinas, confetis y gritos de Carnaval. La alegría de los otros me espantaba. (LISPECTOR, 2008a, p. 64).

La niña es espectadora del afuera y de su propio desmembramiento que se muestra como una transformación esperpéntica. La muerte ya no está a su alrededor sino en su interior.

Cuando una horas más tarde la atmósfera en la casa se calmó, mi hermana me peinó y me pintó. Pero algo había muerto en mí. Y, como en las historias que había leído sobre hadas que encantaban y desencantaban a las personas, yo había sido desencantada; no era ya una rosa, era de nuevo una simple niña. Bajé a la calle y allí de pie no era una flor, era un payaso pensativo de labios encarnados. (LISPECTOR, 2008a, p. 64)

El fantasma de la enfermedad de la madre convive con la niña, su "yo" siente morirse con ese objeto de amor. La posibilidad de ser feliz hace aflorar el sentimiento de culpa que se suma a las formas fantasmagóricas de la melancolía: "En mi hambre de sentir éxtasis, a veces empezaba a sentirme alegre, pero con un remordimiento me acordaba del estado grave de mi madre y de nuevo me moría" (LISPECTOR, 2008a, p. 64).

La palabra "hambre" encierra, en este cuadro de melancolía, un sentido voraz que adelanta el procedimiento de la identificación posible con el objeto, identificación que sólo puede realizarse por la incorporación total del mismo. En su trabajo sobre la melancolía, Freud define la sustitución del amor al objeto por una identificación como un importante mecanismo en las afecciones narcisistas y agrega:

[...] la identificación es la fase preliminar de la elección de objeto, y la primera forma ambivalente en su expresión, utilizada por el yo para escoger un objeto. Quisiera incorporárselo, y correlativamente a la fase oral o canibalística del desarrollo de la libido, ingiriéndolo, o sea devorándolo [...]. (FREUD, 1997, p. 2095)

Finalmente, lo que queda de la rosa le otorga la última esperanza de salvación. Como dijimos en un principio, la rosa puede nacer y despertar algo nuevo y la niña se aferra a esa posibilidad: 
Recién horas después llegó la salvación. Y si de prisa me aferré a ella era porque necesitaba salvarme. Un niño de unos 12 años, lo que para mí significaba un muchacho, un niño muy bonito se paró ante mí y con una mezcla de mimo, grosería, juego y sensualidad, cubrió mis cabellos ya lacios, con confeti: por un instante nos quedamos frente a frente, sonriendo sin hablar. Y yo entonces mujercita de 8 años, consideré por el resto de la noche que finalmente alguien me había reconocido: yo era, sí, una rosa (LISPECTOR, 2008a, p. 64).

En la melancolía no se logra diferenciar un "yo" de un no "yo", la identificación es total, se ha devorado al objeto. No es como una rosa sino es la rosa misma.

\section{"La imitación de la rosa"}

En este cuento, como en "Restos de Carnaval", el título nos anticipa un estado de melancolía, la imitación como sustitución e incorporación del objeto, como trasmutación de la búsqueda de sí. Y, como en el cuento anterior, la flor aparece como objeto a poseer.

Laura, la protagonista, llega de una Institución donde estuvo internada y debe reinsertarse en la vida cotidiana íntima y social de manera natural. Pero ella ya no es la misma, algo ha cambiado en su ser, algo se ha perdido; su mirada recorre el universo de su hogar como si fuera desconocido. Trata de reconstruir su vida ensayando un ritual que la devuelve a un mundo rutinario donde encuentra una aparente seguridad.

La melancolía se constituye desde el principio de la historia, en la nostalgia de los tiempos felices, en un torbellino de ideas que sólo existen en su mente y que no pueden concretarse.

Laura se siente alienada por el mandato social, por el "deber ser". Por eso sólo puede pensar, vive a través del pensamiento. En su alienación, ha perdido su yo. Está paralizada y no hay acción posible en el universo de la melancolía. Tiene intenciones de hacer muchas cosas pero no logra hacer nada.

A través del fluir de la conciencia, Laura trata de recuperar su integridad pero sólo logra recordar e imaginar aquello que la hace sentir disminuida; ha perdido el sentimiento de sí. 
Mientras tanto, ella hablaría con Carlota sobre cosas de mujeres, sumisa a la voluntad autoritaria y práctica de Carlota, recibiendo de nuevo la desatención y el vago desprecio de la amiga, su rudeza natural, y no más aquel cariño perplejo y lleno de curiosidad, viendo, en fin, a Armando olvidado de la propia mujer. Y ella misma regresando reconocida a su insignificancia. (LISPECTOR, 2008b, p. 65)

Sus pensamientos, como secuencias fotográficas del pasado y de un presente efímero, le otorgan imágenes que luchan por reconstruir su "yo" perdido, desintegrado. Para combatir el dolor se aferra a la idea de volver a lo cotidiano, a cumplir con un mandato, a respetar un orden de prioridades, a poder temporalizar las tareas hogareñas, a dedicarse al cuidado de su marido, a disfrazarse de una Laura que está ausente, usando el mismo vestido que solía, tratando de imitar a una Laura que ya no es.

En su mente conviven por un lado, las ansias de reconstruirse y por el otro, el dolor de lo que se ha perdido, la tristeza de no haber sido madre, los recuerdos de los desprecios de su amiga y la indiferencia de su esposo.

Laura no puede actuar. Sólo piensa y contempla su vida desde el dolor y la melancolía. Todo está en su mente. Es una mímesis de lo que debería hacer y de quién debería ser.

El tiempo de Laura es eterno, vive una continuidad propia de la alienación. No encuentra energía psíquica para investir un objeto fuera de su "yo", por lo que ella misma vive como perdida.

La melancolía se instala y la lleva a vivir una dualidad permanente, por un lado, recomponer su vida familiar se convertiría posiblemente en un camino hacia la identificación de un objeto de amor y, por el otro, ese mismo camino es en donde su sumisión a un mandato social se la va devorando de a poco, despersonalizándola, desintegrándola hasta el punto de no reconocerse. Para seguir viviendo necesita repetirse y convencerse de que todo está en orden.

\footnotetext{
Oh, que bueno era estar de vuelta, realmente de vuelta, sonrió ella satisfecha. Tomando el vaso casi vacío, cerró los ojos con un suspiro de dulce cansancio. Había planchado las camisas de Armando, había hecho listas metódicas para el día siguiente, calculando minuciosamente lo que iba a gastar por la mañana en el mercado, realmente no había parado un solo instante. Oh, que bueno era estar de nuevo cansada (LISPECTOR, 2008b, p. 68).
}

En su imaginación, cree que ordenar su casa y cumplir con la rutina le otorga un orden interior, siente que ya no es tan detallista, que se está liberando, que puede ser 
como cualquier mujer, más humana y falible y sobre todo, que ha dejado atrás el dolor: "[...] Y como a todo el mundo, cada día la fatigaba; como todo el mundo, humana y perecedera. No más aquella perfección. No más aquella cosa que un día se desparramara clara, como un cáncer en su alma" (LISPECTOR, 2008b, p. 69).

Pero en realidad el torbellino de ideas termina devorándola, como lo hacía el dolor con su alma. Como una manía se repite lo que debe hacer, trata de convencerse de que es feliz por "estar de regreso" pero su obsesión por conseguirlo no le permite ver que ya no es la misma, que su "yo" está desintegrado, algo se ha perdido aunque no sabe bien lo que ha perdido. Freud (1997) considera que en la melancolía no está claro lo que se ha perdido y se refiere a la pérdida como una pérdida objetual que escapa a la conciencia. Para Agamben (1995), la melancolía es la capacidad fantasmática de hacer aparecer como perdido un objeto inapropiable.

Laura vive una dualidad melancólica. Su universo, el que trata de restituir, se constituye de lo deseado y de lo aborrecible: "Abrió los ojos pesados de sueño, sintiendo el buen vaso, sólido, en las manos, pero los cerró de nuevo con una confortada sonrisa de cansancio, bañándose como un nuevo rico, en todas sus partículas, en esa agua familiar y ligeramente nauseabunda" (LISPECTOR, 2008b, p. 69).

La melancolía ha provocado en Laura la pérdida de un sentimiento de sí, siente que la indiferencia de los otros la libera de ser alguien especial, su lazo con la vida es cumplir el mandato establecido de su rol de ama de casa y de esposa. Cree reconstituir su yo en el cumplimiento de esa demanda pero su entorno le devuelve la imagen de su desmembramiento a cada instante. Se repite que ya no sufre la angustia de estar internada, que ahora se siente protegida entre sus paredes y entre los suyos, pero esa vida hogareña de soledad e incomprensión se la devora de a poco.

El tiempo de Laura es el tiempo de la melancolía, el de la alienación, vive en un eterno devenir del que no puede tomar distancia. La continuidad de sus pensamientos la sostienen y ella se reafirma en la repetición. Todo se dispara en su mente como una cámara fotográfica que no se puede detener.

El sujeto no tiene lugar propio, es el objeto el que le otorga existencia pero Laura ha perdido su objeto de amor, sujeto y objeto han quedado alienados.

El "yo" desmembrado intenta una constante imitación, no sólo de las acciones que supuestamente le van a devolver su integridad, sino también imita un aspecto de mujer que se encuadra en "su" modelo a seguir, que sólo puede vestir un vestido marrón 
con cuello de encaje: "El vestido marrón combinaba con sus ojos y el cuellito de encaje color crema le daba un cierto aire infantil, como de niño antiguo" (LISPECTOR, 2008b, p. 71).

"Ella castaña, como oscuramente pensaba que debía ser una esposa. Tener cabellos negros o rubios era un exceso que en su deseo de acertar, ella nunca había ambicionado" (LISPECTOR, 2008b, p. 72).

En la contemplación de su hogar, Laura repara en unas rosas silvestres, cuya naturalidad y belleza le atraen de manera especial. Las rosas, casi personalizadas, son un poco Laura. La perfección y la belleza que no puede alcanzar la van absorbiendo.

\begin{abstract}
Eran varias rosas perfectas, algunas en el mismo tallo. En cierto momento habían trepado con ligera avidez unas sobre otras, pero después, hecho el juego, tranquilas se habían inmovilizado. Eran algunas rosas perfectas en su pequeñez, no del todo abiertas, y el tono rosado era casi blanco. ¡Hasta parecían artificiales!, dijo sorprendida. Podrían dar la impresión de blancas si estuvieran completamente abiertas, pero con los pétalos centrales envueltos en botón, el color se concentraba y, como el lóbulo de una oreja, se sentía el rubor circular dentro de ellas. ¡Qué lindas son!, pensó Laura sorprendida (LISPECTOR, 2008b, p. 73).
\end{abstract}

Las rosas son el anuncio de algo que puede cambiar; su belleza la conduce a girar el enfoque de su pequeño universo. En ellas hay algo de Laura, en la pureza, en la apariencia superficial, en la palidez de su aspecto pero también son lo que le falta a Laura, la perfección y la belleza tan anhelada, la posibilidad de asir un objeto que le permita restituirle su "yo".

Laura considera que las rosas son tan bonitas que podría regalárselas a su amiga, quiere desviar su atención, olvidarse de ellas, de su nueva obsesión. Se siente amenazada por esa atracción obsesiva que la aleja de su cotidianeidad, no quiere ser ella nuevamente un objeto de observación, la desestabiliza pensar que la mirada de los otros le devolverá una imagen enferma y distorsionada.

Era necesario tener cuidado con la mirada asustada de los otros. Era necesario no dar nunca más motivo de miedo, sobre todo con eso tan reciente. Y, en particular, ahorrarles cualquier sufrimiento de duda. Y que nunca más tuviera necesidad de la atención de los otros, nunca más esa cosa horrible de que todos la miraran mudos, y ella frente a todos. Nada de impulsos (LISPECTOR, 2008b, p. 75).

La belleza de esas rosas se ha vuelto embriagadora, no puede reprimir su voraz deseo de apropiarse de ellas, tendrá por primera vez su objeto deseado, su objeto de 
pertenencia. Laura siente que nada le es propio: "Laura se asustó un poco: porque las cosas nunca eran suyas. Pero esas rosas lo eran" (LISPECTOR, 2008b, p. 76).

En su desorden melancólico, Laura experimenta por las rosas una atracción tan intensa, erótica, que quiere poseerlas sin reconocer que se trata de un objeto de contemplación, de lo inasible. En relación con estos conceptos, Agamben manifiesta:

[...] la incapacidad de concebir lo incorpóreo y el deseo de hacer de ello objeto de abrazo son las dos caras del mismo proceso, en el transcurso del cual la tradicional vocación contemplativa del melancólico se revela expuesta a un trastorno del deseo que la amenaza desde dentro (AGAMBEN, 1995, p. 49).

Las rosas conllevan la dualidad misma en la que vive el melancólico, por un lado la belleza parece abarcar el instante como eterno, es acercarse a la perfección y apropiarse de ella en el goce y la felicidad y, por otro lado, es la caducidad de la vida y el dolor ante la fugacidad del tiempo. Muerte y vida en la mirada del ser melancólico.

Laura trata de expiar su culpa por el deseo de tener las rosas adjudicándole la impronta caducidad de su esencia. Ya no puede escapar de tan maravillosa contemplación pero la contradicción la asalta y la persigue como un fantasma interior. Una parte de sí piensa que debería regalarlas, porque todo lo bello no le pertenece. Y como anunciando la identificación total con ese objeto de belleza y perfección, Laura ya no sólo habla de lo bello que no se puede tener, sino de lo bello que no se puede "ser": "Y también que una cosa hermosa era para ser dada o recibida, no sólo para tenerla. Y sobre todo, nunca para 'ser"” (LISPECTOR, 2008b, p. 77).

El deseo de tener las rosas la atormenta y la conduce a la angustia de la eterna contradicción en sus decisiones, pero siempre vuelven a su mente las palabras y el gesto de su médico que le asegura de su salud. Sabe que ya no es necesario mostrar coherencia a nadie, que nada tiene que probar, sabe que esas rosas pueden ser suyas y que son un alimento para su alma, son un dulce bocado de belleza y tranquilidad.

Cuando María, su sirvienta, se lleva las rosas para regalarlas, Laura siente un vacío angustiante, vuelve a perder su objeto de identificación aunque su obsesión con el mismo no permite la separación y su lazo con las rosas se vuelve más intenso aún.

Y las rosas le hacían falta. Habían dejado un lugar claro dentro de ella. Si se retira de una mesa limpia un objeto, por la marca más limpia que éste deja, se ve que alrededor había polvo. Las rosas habían dejado un lugar sin polvo y sin sueño dentro de ella. En su corazón, aquella rosa que por lo menos habría 
podido quedarse sin perjudicar a nadie en el mundo, faltaba. Como una ausencia muy grande. En verdad, como una falta (LISPECTOR, 2008b, p. 79).

Con las rosas, Laura siente que ha perdido una parte de sí, pero su pensamiento sigue unido a ellas porque no puede separar su "yo" del objeto, continúa su sentimiento de identificación. Vuelve a estar perdida y alienada como cuando había regresado a su casa y fantaseaba que un mágico e insistente ritual hogareño le devolvería su integridad.

Laura ya no puede tener todo bajo control, la falta corpórea de su objeto la vuelve extraña y ausente. La melancolía acrecienta aun más la distancia que la separa de su marido, se hace palpable la indiferencia de su esposo y el temor que aún guarda en su gesto desconfiado.

No está lista para la cena programada, se encuentra abstraída, sentada como ausente, ha otorgado a su hogar una tranquilidad que preocupa a su esposo. Con el arrebato de una culpa que la devora, Laura confiesa la causa de su estado como si pudiera ser explicado y entendido.

- No pude impedirlo - dijo ella, y en su voz había la última piedad por el hombre, la última petición de perdón que ya venía mezclada a la altivez de una soledad casi perfecta - . No pude impedirlo - repitió entregándole con alivio la piedad que ella consiguiera con esfuerzo guardar hasta que él llegara -. Fue por las rosas - dijo con modestia (LISPECTOR, 2008b, p. 81).

En su afán de imitar a las rosas, de incorporar algo de esa perfección y belleza, termina devorándoselas como objeto de elección, perdiendo definitivamente su "yo".

$\mathrm{Su}$ esposo la observa como si se tratara de una imagen fotográfica. En complicidad con esa ausencia, logra reconocer que ella ha luchado por no ser inalcanzable pero definitivamente se ha perdido. Su pose trémula indica estar a punto de partir definitivamente a algún lugar.

\section{Conclusión}

El análisis de los cuentos "Restos de Carnaval” y "La imitación de la rosa" nos lleva a reflexionar sobre la construcción de la melancolía como síntoma contextual de la modernidad y como preocupación en la narrativa de Clarice Lispector. La autora nos acerca a un desciframiento de los temas más profundos que preocupan al hombre moderno. 
Mediante el análisis de los cuentos mencionados se ha podido comprobar que los mismos presentan puntos de contacto en el planteo acerca de la melancolía. En "Restos de Carnaval" la mirada es desde una niña que piensa y siente como una adulta porque el dolor le arrebata sus ilusiones y su candidez; en "La imitación de la rosa", la visión es de una mujer adulta que muchas veces se siente una niña en la fragilidad de su mundo solitario. Ambas se encuentran alienadas, una por la enfermedad de la madre y la otra por la cotidianeidad y el mandato patriarcal. No pueden constituir plenamente su "yo" y no tienen energía psíquica como para investir un objeto separado del "yo".

Tanto la niña como Laura, las protagonistas, pierden el sentimiento de sí, viven inmersas en un devenir que no pueden detener.

La rosa, como objeto común en los dos cuentos, conlleva la dualidad del espíritu melancólico, por un lado, representa la salvación, la trascendencia y, por otro, es lo efímero y lo inconsistente. La rosa es, a la vez, la esperanza en medio de un mundo carente de sentido, vacío de espiritualidad pero también es lo inasible, aquello que no podemos abrazar. Pero sobre todo, la "rosa" es el objeto elegido de identificación que termina siendo devorado.

La devoración de la rosa es la confirmación de una soledad ontológica de la que el hombre moderno no puede escapar.

Saudade es un poco como hambre. Sólo ocurre cuando se come la presencia. Pero a veces la saudade es tan profunda que la presencia es poco: se quiere absorber a la otra persona toda. Estas ganas de uno ser el otro para una unificación completa es uno de los sentimientos más urgentes que existen en la vida (LISPECTOR, 2008c, p. 85). 


\section{REFERÊNCIAS}

AGAMBEN, Giorgio. Estancias. La palabra y el fantasma en la cultura occidental. Valencia: Pre-Textos, 1995.

ANDRADE, Ana Luiza. Saturno Devorador da Modernidade: Imagens/Sensações. Revista Brasileira de Literatura Comparada, ABRALIC/Florianópolis, n. 4, 1998.

FREUD, Sigmund. Duelo y Melancolía 1915 (1917). In: Obras Completas. tomo XCIII. Trad. Luis López Ballesteros y De Torres. Madrid: Biblioteca Nueva, 1997.

LISPECTOR, Clarice. Restos de carnaval. In Revelación de un mundo. Buenos Aires: Adriana Hidalgo editora, 2008a.

. La imitación de la rosa. In: Cuentos reunidos. Madrid:Ediciones Siruela, 2008b. Saudade. In: Revelación de un mundo. Buenos Aires: Adriana Hidalgo editora, 2008c. 